\section{Epidermoid accessory splenic cyst masquerading as a pancreatic mucinous cystic neoplasm}
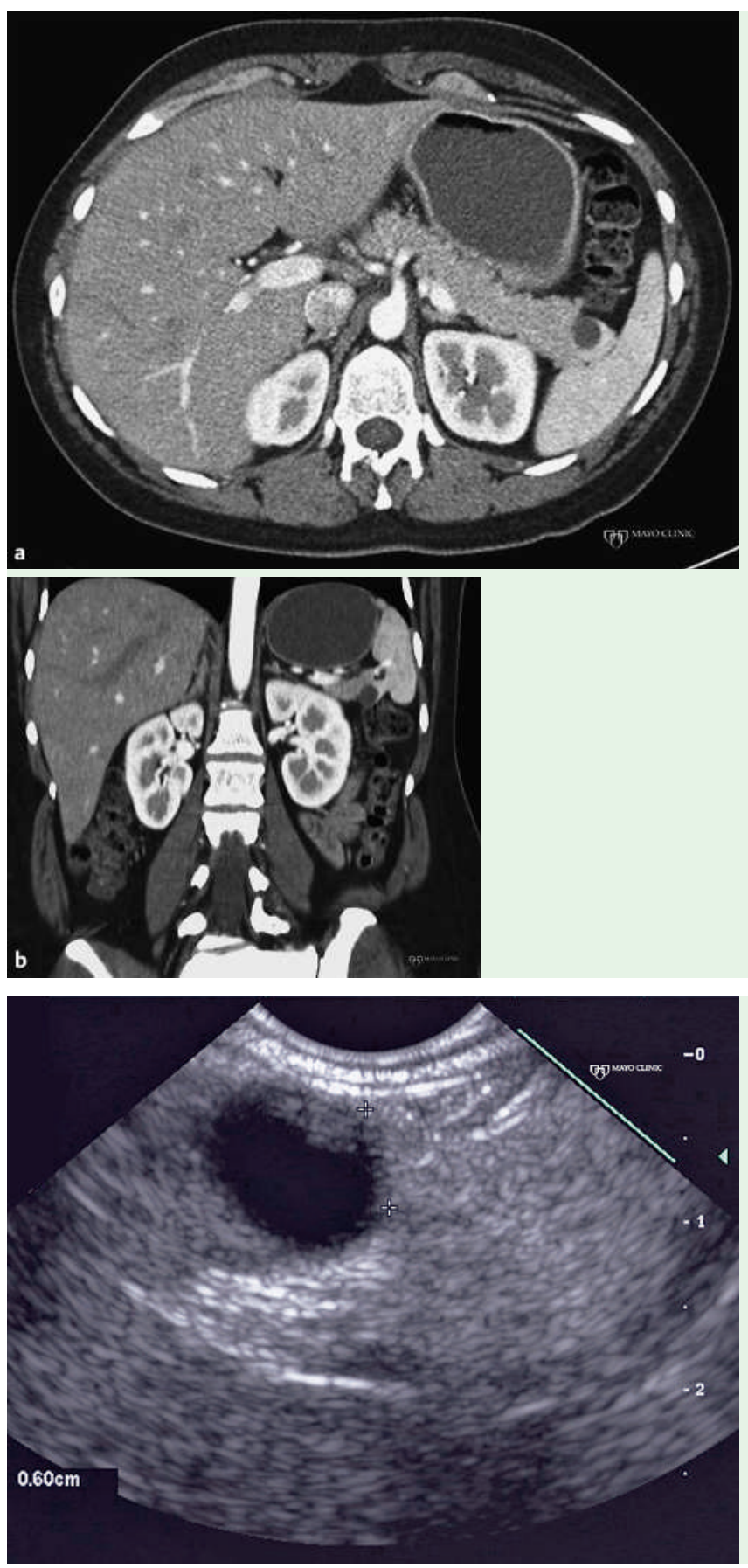

Fig. 1 a Transverse and $\mathbf{b}$ coronal views of a cystic lesion at the pancreatic tail bordered by did not enhance or have features of calcification, septation, or satellite lesions.

Fig. 2 A thin-walled cystic lesion bordering and emanating from splenic parenchyma, having a 6-mm area of abutment with pancreatic parenchyma. splenic tissue, which
A carcinoembryonic antigen (CEA) value of $>1000 \mathrm{U} / \mathrm{ml}$ in pancreas cyst fluid is considered almost pathognomonic for a mucinous cystic neoplasm. A 32-year-old woman underwent abdominal computed tomography (CT) for evaluation of right upper quadrant pain, which revealed a 10-mm pancreatic tail cyst ( $\mathbf{F i g . 1 a , b}$ ). The sharply demarcated cyst without septation did not communicate with the pancreatic duct. Follow-up CT, 4 months later, revealed interval growth to $16 \mathrm{~mm}$. Analysis of cyst fluid obtained at endoscopic ultrasonography (EUS) revealed an elevated CEA level (1377 U/ml).

Following referral, repeat EUS revealed a $15 \times 12$-mm cystic mass that appeared to be extrapancreatic, abutting the pancreas and spleen. A smooth rim of tissue was noted within the cyst that had the same echodensity and pattern as the adjacent spleen ( $\bullet$ Fig. 2, $\bullet$ Video 1 ). While it was unclear whether this represented retained blood secondary to the prior EUS fine-needle aspiration (FNA) or a solid component within a cystic pancreatic neoplasm, it was felt that the cyst might have been located within the spleen or an accessory spleen. However, despite the uncertainty raised by EUS as to the origin of the cyst, the CT findings and elevated CEA level all strongly suggested the presence of a cystic pancreatic neoplasm. A subsequent distal pancreatectomy and splenectomy revealed a cyst located between and densely adherent to the pancreas and spleen. Surgical pathology revealed an epidermoid cyst arising within an accessory spleen ( $\bullet$ Fig. 3a, b). Approximately $10 \%$ of benign nonparasitic splenic cysts are epidermoid cysts, which may be located within the spleen or an accessory spleen [1-3]. They are commonly associated with an elevated CA 19-9 level and the CEA level has been reported to be $>1000 \mathrm{U} / \mathrm{ml}$ [4]. The pancreatic cyst differential is broad and extrapancreatic cysts may masquerade as cystic pancreatic neoplasms. Furthermore, this report highlights the fact that the CEA level is only one feature to be considered, and markedly elevated levels do not absolutely indicate a mucinous cystic neoplasm.

\section{Video 1}

Video shows thin-walled cystic lesion bordering and emanating from splenic parenchyma, with a 6-mm area of abutment with pancreatic parenchyma. 


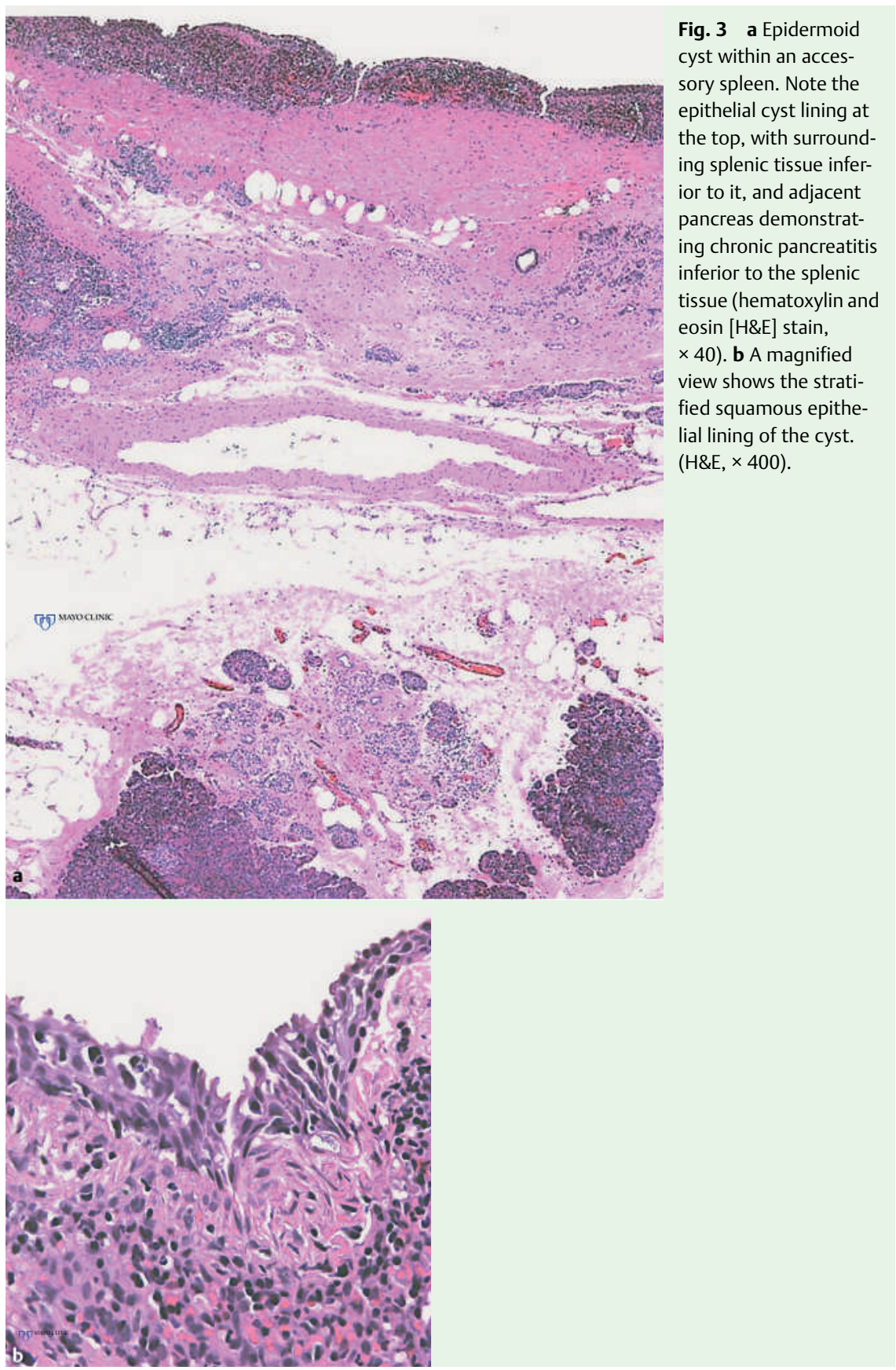

Endoscopy_UCTN_Code_CCL_1AF_2AZ_3AB

Endoscopy_UCTN_Code_CCL_1AF_2AZ_3AD

F. C. Gleeson, M. L. Kendrick, S. T. Chari, L. Zhang, M. J. Levy

Division of Gastroenterology and Hepatology, Mayo Clinic Foundation, Rochester,

Minnesota, USA

\section{References}

1 Robbins FG, Yellin AE, Lingua RW et al. Splenic epidermoid cysts. Ann Surg 1978; 187: $231-235$

2 Avital S, Kashtan H. A large epithelial splenic cyst. N Engl J Med 2003 27; 349: 2173 - 2174

3 Ru K, Kalra A, Ucci A. Epidermoid cyst of intrapancreatic accessory spleen. Dig Dis Sci 2007; 52: 1229-1232

4 Mori M, Ishii T, Iida T et al. Giant epithelial cyst of the accessory spleen. J Hepatobil Pancreat Surg 2003; 10: $118-120$

\section{Bibliography}

DOI 10.1055/s-2007-995735

Endoscopy 2008; 40: E141-E142

(c) Georg Thieme Verlag KG Stuttgart · New York . ISSN 0013-726X

\section{Corresponding author}

M. J. Levy, M.D.

Mayo Clinic College of Medicine,

Division of Gastroenterology and Hepatology,

200 First Street SW, Charlton 8,

Rochester, MN 55905.

Fax: +1-507-266-3939

levy.michael@mayo.edu 